\title{
The significance of performance appraisal for innovation, in selected South African organisations
}

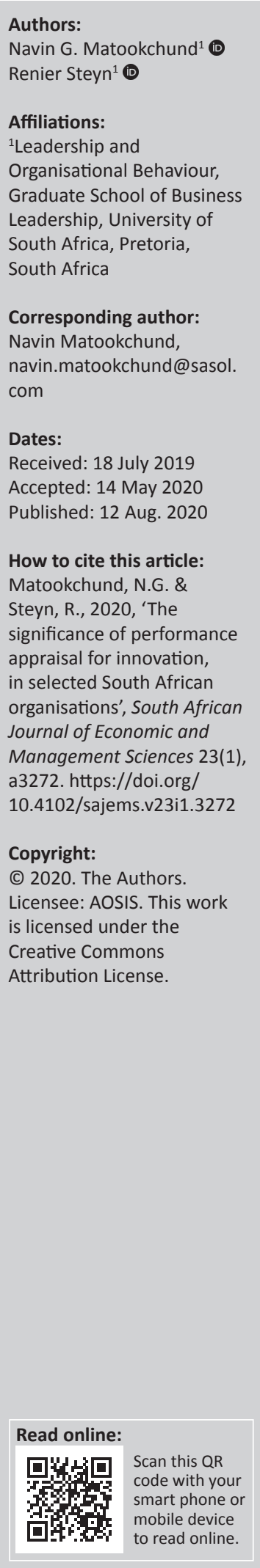

Background: It is evident from Western literature that performance appraisal (PA) results in innovation. However, evidence of empirical research on the different models on the PAinnovation link is seemingly lacking within the South African environment. The South African context may be unique, given the legislative framework within which PA is administered.

Aim: To provide clarity on the specific PA-innovation models within the South African context.

Setting: The PA-innovation relationship is contextualised within the South African context, across more than 50 organisations and more than 3000 randomly selected employees.

Methods: A quantitative research approach was adopted, using a cross-sectional survey design as the study involved 3180 employees from 53 organisations. Seven variables were included in the model, namely PA, individual innovative behaviour (IIB), proactive personality $(\mathrm{PP})$, transformational leadership (TL), corporate entrepreneurship (CE), work engagement (WE) and affective commitment (AC).

Results: The results reveal that PA directly influences innovation. The PA-innovation relationship is mediated by $\mathrm{WE}$ and $\mathrm{AC}$, with WE having the most significant effect. Furthermore, TL and CE moderate the PA-innovation relationship, with TL having the strongest effect and CE having almost no effect. Additionally, PP does not moderate the PAinnovation relationship. Managing employees with TL practices and instilling WE may be at the root of innovation in organisations.

Conclusion: The research contributes to the body of knowledge on the PA-innovation link, and the outcomes of this study are expected to be of value to all stakeholders and may assist managers to appropriately assign resources to particular organisational variables, thereby enhancing innovation within organisations. This evidence-based information would help managers to increase innovative behaviour, performance, competitive advantage, organisational success, growth and organisational survival.

Keywords: Corporate entrepreneurship; innovation; organisational commitment; performance appraisal; proactive personality; South Africa; transformational leadership; work engagement.

\section{Background}

Innovation is an essential success factor for organisations to endure the harsh business climate (Abbaspour 2015; Ling \& Nasurdin 2011; Runfeng 2011). In addition, in order to enable the organisation to enhance performance, competitive advantage, success, expansion and its chances of continued existence, innovation is crucial (Jafri 2010; Ling \&Nasurdin 2011). Focusing on innovation is at the root of a competitive advantage in organisations (Jafri 2010; Wu et al. 2016). By the same token, studies (Abbaspour 2015; Subramaniam \& Youndt 2005) have shown that innovation leads to a competitive advantage and organisational growth.

There are a plethora of studies investigating and evaluating the various variables relating to innovation. Some of these variables include: affective commitment (AC) (Jafri 2010), proactive personality (PP) (Seibert, Kraimer \& Crant 2001; Tai \& Mai 2016), organisational climate (Michaelis, Stegmaier \& Sonntag 2010; Shanker, Bhunugopan \& Fish 2012), organisational culture (Michaelis et al. 2010; Tipu, Ryan \& Fantazy 2012), leadership (Oke, Munshi \& Walumbwa 2009; Tipu et al. 2012), work engagement (WE) (Agarwal 2014; Agarwal et al. 2012), performance appraisal (PA) (Aktharsha \& Sengottuvel 2016; Choi, Moon \& Ko 2013; Runfeng 2011) and other human resource practices (HRPs) (Aktharsha \& Sengottuvel 2016; Dalota \& Perju 2010). However, it must be noted that a limited number of variables were used in designing these researches. 
Performance appraisal is important to organisations, and a measure of the quality of human resource management (Aggarwal \& Thakur 2013). Several authors (Grote 1996; Khoury \& Analoui 2004; Nickols 2007), point out that organisations invest many hours and a lot of money in PA. Nickols (2007) provides an example of a South African telecommunications company in which the annual costs of PA were approximately US\$1.1 million and an example of a Western company in which the costs of staff time spent on PA were conservatively estimated to be in the region of US\$100 million per year. Getting PA wrong has negative consequences that include reduced employee productivity, employee disappointment, employee stress, employee depression, reduced employee morale and diminishing motivation (Blankenship 2002; Nickols 2007). Adding these psychosocial costs to the operational costs associated with PA can negatively influence an organisation's bottom line, particularly when suitable value is not extracted from an organisation's PA system (Khoury \& Analoui 2004; Nickols 2007).

Numerous empirical research studies (for example, Aktharsha \& Sengottuvel 2016; Bal, Bozkurt \& Ertemsir 2014; Choi et al. 2013; Ling \& Nasurdin 2011; Runfeng 2011; Shipton et al. 2006) provide evidence of a relationship between PA and innovation. These studies provide simple models explaining this relationship mainly within the Western context (Aktharsha \& Sengottuvel 2016; Bal et al. 2014; Choi et al. 2013; Ling \& Nasurdin 2011; Runfeng 2011; Shipton et al. 2006). Research on the PA-innovation relationship using more complex models and specifically investigating these relationships within the South African context is lacking. The South African context may be particularly unique as there exists a need to check PA for compliance with the requirements of pertinent labour laws (Swanepoel, Erasmus \& Schenk 2008). This study attempts to both clarify the nature of specific drivers of innovation and contextualise the study within the South African context.

\section{Research problem}

Literature suggests that the implementation of PA results in innovation. However, this link is complex, and includes many other variables. The proper quantification with regard to the specific mediator and moderator variables that drive innovation is not explored satisfactorily, specifically within the South African context. Lacking this distinction of information on the PA-innovation relationship, human resource practitioners and managers may improperly assign resources to particular organisational variables, hampering organisational success. This article aims to empirically test the significance of PA for innovation, in selected South African organisations. Different models on the PA-innovation link will be investigated by applying mediators such as WE and $\mathrm{AC}$, along with moderators such as PP, transformational leadership (TL) and corporate entrepreneurship (CE) climate. Ultimately, a complex data-based model of the PA-innovation link will be produced.

\section{Literature review}

Most successful organisations employ PA among other HRPs to enhance organisational performance and employee efficiency (Ayers 2013; DeNisi \& Pritchard 2006). According to Ahmed, Mohammad and Islam (2013), PA is responsible for continuous improvement within the organisational setting. The literature reflects that PA is an important HRP. For example, Boswell and Boudreau (2000), and Judge and Ferris (1993) indicate that PA is one of the main sub-practices of the nine common HRPs.

Performance appraisal is the method of witnessing and assessing an employee's performance, formally noting the evaluation, and providing feedback on key performance areas of improvement to the employee (Muller, Bezuidenhout \& Jooste 2011). Additionally, Matookchund (2019) suggests that PA refers to an officially organised means that managers use annually to gauge a subordinate's actual performance, along with strengths and weaknesses in an effort to develop and reward the employee. Performance appraisal is a commonly explored topic in human resource management. For instance, DeNisi and Pritchard (2006), and Siaguru (2011), indicate that almost a century has been devoted to the study of PA by human resource practitioners and researchers. Just about all organisations make use of some sort of PA system (DeNisi \& Pritchard 2006; Mitchell 2010).

Given the above, it is notable that PA and innovation both play a significant role within the organisational context. As highlighted by Chen and Huang (2009), organisations with extremely effective PA methods attain substantial innovation results. Furthermore, a number of studies indicate that there is a significant and positive relationship between PA and innovation (Aktharsha \& Sengottuvel 2016; Bal et al. 2014; Choi et al. 2013; Shipton et al. 2006). This adds credence to the view that the effective implementation of PA results in innovation.

There is an abundance of antecedents to innovation. Examples listed earlier include leadership styles, organisational climate, $\mathrm{PP}$, commitment and engagement. In considering the link between leadership and innovation, Sethibe and Steyn (2015), for example, note that the majority of studies concentrated on TL rather than other leadership styles. According to Burns (1978), TL is a collaboration between leaders and subordinates in an effort to elevate each other's principles and motivation levels. A transformational leader is someone who motivates subordinates to achieve more than expected (Bass 1985). Transformational leaders inspire followers to accomplish organisational goals, stress the need for organisational change and promote innovation (Alsalami, Behery \& Abdullah 2014). Transformational leadership has a strong and positive relationship with innovation (Oke et al. 2009; Sethibe \& Steyn 2016; Tipu et al. 2012). Research conducted by Sethibe and Steyn (2016), found no direct or indirect link between transactional leadership and innovation. This notion is reinforced by the work led by Oke et al. (2009) who conclude that TL is far more suitable than transactional leadership in fostering innovation. 
The second variable of interest is the CE climate, which has been a significant topic of interest for researchers in recent years (Dess et al. 2003; Phan et al. 2009). Hornsby, Kuratko and Zahra (2002) define CE very broadly as the development and implementation of fresh ideas within an organisation, while McFadzean, O'Loughlin and Shaw (2005) define it as an effort to promote innovation within the organisation. Furthermore, CE is centred around five factors: management support, work discretion, rewards, time available and organisation boundaries (Hornsby et al. 2002; Morris, Kuratko \& Covin 2010). It appears that corporate climate may also be prominent in promoting innovation. Corporate climate is an essential antecedent to innovation (Michaelis et al. 2010; Shanker et al. 2012). Several empirical studies provide evidence that there is a strong connection between innovation and climate (Lin \& Liu 2012; Michaelis et al. 2010; Shanker et al. 2012).

It is stated by many that the PP of employees also contributes to innovation in organisations. Bateman and Crant (1993) suggest that PP is a character trait embodying proactive behaviour. Furthermore, PP is seen as a key characteristic of employees in successful organisations. Matookchund (2019) suggests that focusing on the recruitment of proactive employees rather than managing them with TL practices may be at the root of innovation in organisations. It is not surprising, then, that employees with a PP are more likely to seek out new ways to improve their work performance and implement new ideas (Kim, Hon \& Lee 2010). Some studies (for example Seibert et al. 2001; Tai \& Mai 2016) show that PP has a positive and strong connection with innovative behaviour. Considering the foundation for innovation, other studies (Fuller \& Marler 2009; Seibert et al. 2001) theorise that $\mathrm{PP}$ is the basis of innovative behaviour.

Organisational commitment may also influence innovation. Organisational commitment is regarded as a psychological state from a multidimensional perspective, which consists of three distinct types of commitment, that is, affective, normative and continuance commitment (Allen \& Meyer 1990; Meyer \& Allen 1997). The focus of this research will be on AC, as it is often this element of organisational commitment that is presented as the central element (Lamba \& Choudhary 2013; Steyn, Bezuidenhout \& Grobler 2017). Affective commitment is regarded as an employee's 'emotional attachment to, identification with, and involvement in the organisation' (Meyer \& Allen 1997:67). It is regarded as an emotional attachment that employees feel toward the organisation and their jobs, and the desire to stay loyal (Mei, Ong \& Pei 2017; Meyer \& Allen 1997). In a study by Jafri (2010), AC is positively related to innovative behaviour, and continuance commitment is negatively related to innovative behaviour.

The last variable of concern is WE. Many scholars have offered a definition for WE over the years, but Schaufeli et al. (2002) have offered the most accepted definition. Engagement is defined as a 'positive, fulfilling, work-related state of mind that is characterised by vigour, dedication, and absorption' (Schaufeli et al. 2002:74). According to Agarwal (2014) and
Agarwal et al. (2012), WE correlates positively with innovative behaviour. These authors also provide evidence that WE mediates the relationship between leader-member exchange and innovative behaviour, and partially mediates intention to quit (Agarwal et al. 2012).

Interestingly, TL, CE climate, PP, AC and WE are important contributors to innovation which is quite apparent from the literature above. Theoretically, the study considers the General Systems Theory and the Input-TransformationOutput model, which in their simplest form indicate that these variables may be related (Kast \& Rosenzweig 1972; Teece 2018). The literature is however not clear on the nature of the relationship between these variables, particularly if they are modelled together.

\section{Method}

\section{Population, sampling and data collection}

Included in this study are employees from medium-sized to large (more than 60 employees) South African organisations only. Many organisations were requested to participate; finally 53 of these organisations agreed and a total of 3180 completed questionnaires were returned.

The sample for the 53 selected organisations was not random, but rather a convenience sample. Once the organisations had been identified, 60 respondents were selected at random from each of the organisation's employee records $(N=3180)$.

This data was collected manually through paper-based questionnaires as part of a research project led by the second author of the study. Ultimately, the sample comprised 3180 employees employed by 53 organisations within South Africa, representing the private sector, parastatals and government departments. The data was gathered as per the ethics guidelines of the University of South Africa (UNISA), and authorisation was obtained from the UNISA Research Ethics Review Committee to use the data as secondary data.

\section{Research approach}

This study made use of a cross-sectional survey design, centring on quantitative data. A quantitative research approach is appropriate for the nature of this study as it freely permits the formation of relationships among variables (Bryman 2012; Punch 2005). This article focuses specifically on secondary data for the quantitative research analysis.

\section{Measuring instruments}

Seven instruments were used in the analysis, namely the quality of a performance appraisal system questionnaire (PA; Steyn 2010), the individual innovative behaviour questionnaire (IIB; Kleysen \& Street 2001), the Utrecht work engagement scale-9 (WE; Schaufeli \& Bakker 2004), a part of the organisational commitment scale, specifically the affective commitment scale portion (AC; Allen \& Meyer 1990), the proactive personality scale (PP; Bateman \& Crant 
1993), a part of the leadership scale, specifically the transformational leadership scale portion (TL; Wolins 2012), and the brief corporate entrepreneurship assessment instrument (CE; Strydom 2013):

- The PA questionnaire, created by Steyn (2010), was used to evaluate the perceived efficacy of PA systems in organisations. The questionnaire was based on human resource management literature (Cascio 2010; Grobler et al. 2006; Swanepoel et al. 2008) which describes the characteristics of an effective PA system. Grobler et al. (2006) provide a full list of necessities for an effective PA system, and the majority of the literature was therefore adapted from these authors. The PA questionnaire comprised 18 statements designed to prompt the respondent's views on the PA process. Respondents had to specify their views for each item on a five-point scale ranging from 1 to 5 as follows: 1 (Absolutely false - this is true in $+/-10 \%$ of all cases), 2 (Somewhat false - this is true in $+/-35 \%$ of all cases), 3 (Neither true nor false), 4 (Somewhat true - this is true in $+/-75 \%$ of all cases), and 5 (Absolutely true - this is true in $+/-90 \%$ of all cases). The lowest score that could be achieved was 18, and the highest was 90. A high score indicates that a traditionally defined PA system was in place and working effectively, while a low score indicates that the respondents were convinced that a traditionally defined PA system was not working in their organisation (Steyn 2010). Furthermore, Steyn reports a Cronbach's alpha of 0.84, indicating internal consistency, and significant correlations (in the expected direction) with results such as turnover intentions $(R=0.311 ; p<0.01)$, job satisfaction $(R=0.281 ; p<0.01)$ and employee engagement $(R=0.318 ; p<0.01)$.

- The IIB questionnaire by Kleysen and Street (2001) was chosen to quantify IIB. According to Kleysen and Street, there is a lack of studies on a multidimensional measure of IIB. The IIB questionnaire contains 14 questions, randomly itemised to avoid possible response order bias. Respondents had to indicate their views for each question on a six-point scale ranging from 1 (Never) to 6 (Always). The lowest score that could be obtained was 14 and the highest 84 . Each of the 14 items was prefaced with the following question: 'In your current job, how often do you ...' (Kleysen \& Street 2001:288). Kleysen and Street report that a measure of inter-correlation between the 14 questions resulted in a Cronbach's alpha of 0.95 and good construct validity. All five factors are strongly correlated with each other, with the highest correlation being between application and formative investigation $(R=0.81 ; p<0.01)$ and the lowest between championing and generativity $(R=0.68 ; p<0.01)$. Kleysen and Street thus suggest that the 14 items can be combined into a single measure of innovative behaviour, and this was done for this research.

- According to Schaufeli and Bakker (2004), and Schaufeli, Bakker and Salanova (2006), the WE scale includes the three founding facets of WE: vigour, dedication and absorption. This questionnaire consisted of nine statements (three vigour statements, dedication statements and absorption statements) that are randomly listed to avoid potential response order bias. Respondents were requested to indicate their views for each statement on a seven-point scale ranging from 0 to 6 as follows: 0 (Never - never), 1 (Almost Never - a few times a year or less), 2 (Rarely once a month or less), 3 (Sometimes - a few times a month), 4 (Often - once a week), 5 (Very Often - a few times a week), and 6 (Always - every day). Schaufeli and Bakker report that for all nine statements, the Cronbach's alpha varies from 0.85 to 0.94 (median $=0.91$ ) across studies done in nine countries. Schaufeli and Bakker further explain that the Cronbach's alpha value for the total data set was 0.9. Schaufeli et al. (2006:701) state that the 'factorial validity of the WE scale was demonstrated using confirmatory factor analysis and the three scale scores have good internal consistency and test-retest reliability'.

- The Organisational Commitment scale is used to measure organisational commitment, and the questionnaire consists of 24 items. The focus will be on AC rather than normative or continuance commitment, as Lamba and Choudhary (2013), and Wright and Kehoe (2007) indicate that AC is far more important to HRPs and organisational performance. The AC scale portion of the questionnaire consists of eight items. Respondents were requested to indicate their views for each item on a seven-point scale as follows: 1 (Strongly disagree), 2 (Moderately disagree), 3 (Slightly disagree), 4 (Neither agree nor disagree), 5 (Slightly agree), 6 (Moderately agree), and 7 (Strongly agree). The minimum score on the AC scale portion of the questionnaire would be 8 and the maximum 56. A high score would indicate that respondents are of the view that there are high levels of commitment and a low score would show low commitment. Allen and Meyer (1990) report that the reliability (that is, coefficient alpha) for the AC scale is 0.87 and the internal consistency is 0.86 . Meanwhile, Steyn (2012) reports a Cronbach's alpha of 0.82 for the Organisational Commitment scale. Allen and Meyer further explain that convergent validity is evident since the Organisational Commitment scale correlated significantly with the AC scale.

- The PP scale, developed by Bateman and Crant (1993), comprised 17 statements designed to elicit the respondent's views on proactive behaviour. Respondents were invited to indicate their views for each statement on a five-point scale ranging from 0 to 4 as follows: 0 (Strongly disagree), 1 (Disagree), 2 (Not sure), 3 (Agree), and 4 (Strongly agree). The lowest score that could be obtained was 0 and the highest 68 . Bateman and Crant report internal reliability with a Cronbach's alpha of 0.89 . By the same token, Bateman and Crant argue that the proactive scale was significantly correlated to all three criterion variables, which is indicative of criterion validity, while discriminant validity was exposed between the proactive scale and intelligence, neuroticism, agreeableness, openness, private self-consciousness and locus of control. 
- The Leadership scale questionnaire developed by Avolio, Bass and Jung (1999) is used to assess transactional and $\mathrm{TL}$ and consists of 21 items. The focus will be on TL rather than transactional leadership, as Sethibe and Steyn (2016) indicate that there is no direct relationship between transactional leadership and innovation, whereas TL is positively and significantly related to innovation. The TL scale portion of the questionnaire consists of 12 items, as described by Wolins (2012), and only this part was utilised for this research. Respondents were requested to indicate their views for each item on a five-point scale ranging from 0 (Not at all) to 4 (Frequently, if not always). The minimum score on the TL scale portion of the questionnaire would be 0 and the maximum 48 . Strydom (2013) reports reliability with a Cronbach's alpha of 0.87 , while Sethibe and Steyn report a Cronbach's alpha of 0.94 for the TL scale portion. Antonakis, Avolio and Sivasubramanian's (2003) results indicate that the Leadership scale questionnaire is both reliable and valid.

- The CE instrument by Strydom (2013) was chosen to quantify CE climate. The CE instrument consists of 20 items and respondents were requested to indicate their views for each item on a scale ranging from 1 (Strongly disagree) to 5 (Strongly agree). The minimum score on the CE instrument would be 20 and the maximum 100. A high score would indicate that respondents are of the view that there are high levels of entrepreneurial support in the organisation, while a low score would show low support for entrepreneurship (Strydom 2013). Strydom reports an adequate reliability score (Cronbach's alpha $=0.810$ ) for the total CE instrument, while also reporting Cronbach's alphas of 0.731, 0.825, $0.740,0.689$ and 0.574 for the subsections management support, work discretion, rewards, time available and organisation boundaries. Outcomes with regard to the organisation boundaries subsection should be viewed with some caution, particularly due to its Cronbach's alpha being below 0.6. Entrepreneurial spirit intensifies with a rise in employee engagement, commitment and job satisfaction and this is indicative of concurrent validity (Strydom 2013). Furthermore, Strydom reports that, when the factor analysis was concluded, all items loaded as expected, with values above 0.5 suggesting factorial validity for the CE instrument.

\section{Conceptual model}

The proposed model (Figure 1) was tested with the PROCESS macro for the Statistical Package for Social Science (SPSS).

\section{Hypotheses}

The following are the hypotheses developed in this study:

- Model 1: The relationship between PA and IIB (where PA relates to IIB) is mediated by WE and AC, and moderated by PP

- Model 2: The relationship between PA and IIB (where PA relates to IIB) is mediated by WE and AC, and moderated by TL

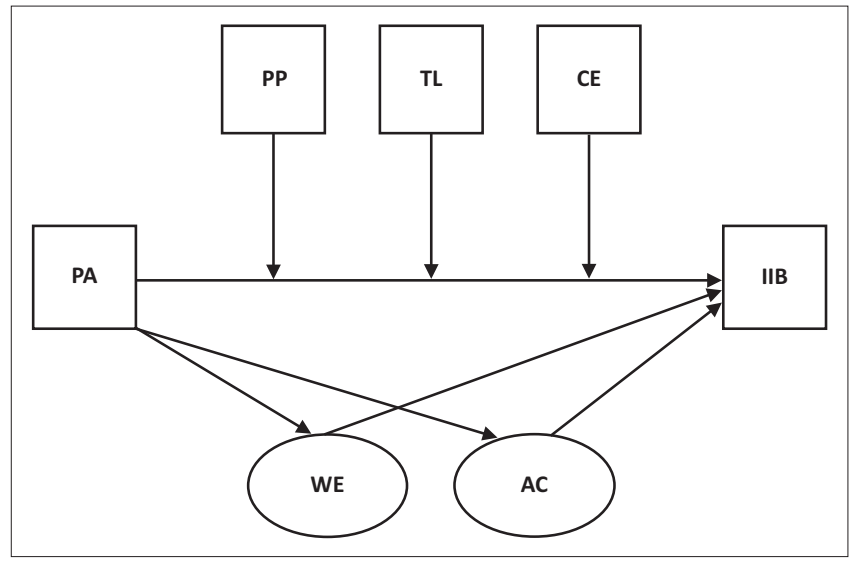

Note: Three models were tested; PA was the independent variable in all models and two mediators (WE and AC) were included in each model. The moderators (PP, TL, and CE) were subsequently added. The dependent variable was IIB.

$\mathrm{AC}$, affective commitment; WE, work engagement; $\mathrm{PA}$, performance appraisal; IIB, individual innovative behaviour; TL, transformational leadership; $C E$, corporate entrepreneurship; $\mathrm{PP}$, proactive personality.

FIGURE 1: Performance appraisal-innovation model with mediator and moderator variables.

- Model 3: The relationship between PA and IIB (where PA relates to IIB) is mediated by WE and AC, and moderated by $\mathrm{CE}$

Each of the hypotheses was evaluated in the PROCESS macro for SPSS to obtain the best-fit PA-innovation model.

\section{Statistical analysis}

Firstly, the standard SPSS was employed to compute demographic characteristics, descriptive and reliability statistics. Then, the PROCESS macro for SPSS was used for the conceptual model assessment.

For descriptive statistics, frequencies and percentages were calculated to provide respondents' demographic characteristics. Then, basic descriptive statistics were calculated for the independent and dependent variables. These included means and standard deviations. Cronbach's alpha coefficients as a measure of internal consistency were also calculated to confirm the reliability of all constructs of the validated instruments. Hair et al. (2009), and Montshiwa and Moroke (2014) recommend that reliability is suitable when the alpha is greater than 0.6. Therefore, all instruments with a Cronbach's alpha above 0.6 were deemed to hold satisfactory reliability.

The mediation and moderation models were assessed with the PROCESS macro for SPSS developed by Hayes (2013). PROCESS performs centring automatically and also utilises bootstrapping to calculate standard errors and confidence levels for the significance of effects.

Model estimation in PROCESS is typically undertaken with ordinary least squares regression-based path analysis, but it is taken further with conditional process analysis, a class of models that allows mechanisms (that is, indirect effects in a path model) to vary systematically as a function of one or 
more moderator variables. Latent variables were not modelled in PROCESS as in structural equation modelling but rather the calculated averages.

The Sobel test was used to test the significance of the mediation effect. The cut-off point for statistical significance was taken as $p<0.01$. Preacher and Hayes (2004) indicate that the Sobel test functions well only in large samples, and the sample size in this study is relatively large $(N=3180)$.

The models that were tested contained two mediators and one moderator as illustrated in Figure 1.

\section{Ethical consideration}

Ethics approval was granted by the University of South Africa, School of Business Leadership Research Ethics Review Committee on 24 April 2018 for the study with the ethics clearance number: 2018_SBL_DBL_003_SD.

\section{Results}

\section{Respondents demographic characteristics}

The data was drawn from the responses of 3180 employees from 53 organisations within South Africa, representing the private sector, parastatals and government departments.

\section{Gender}

The respondents were categorised into the two recognised gender groups. The 2016 Quarterly Labour Force Survey shows that the gender demographic across South Africa as a whole is almost equally spread (Statistics South Africa 2016), and this is very much in line with the gender sample in this study. A total of 1771 (55.7\%) respondents listed their gender as male and 1372 (43.1\%) registered their gender as female, while data was missing for $37(1.2 \%)$.

\section{Race}

Respondents were categorised into four common race groups and this data is in line with the Quarterly Labour Force Survey in the sense that, in the larger South African context, Black people make up the major workforce group, followed by White people, Coloured people and Asian people in descending order (Statistics South Africa 2016). A total of 263 (8.3\%) respondents indicated their race as Asian, 1830 (57.5\%) Black, 263 (8.3\%) Coloured and 787 (24.7\%) White, while data was missing for 37 (1.2\%).

\section{Age}

The 2016 Quarterly Labour Force Survey indicates that the age of the South African workforce ranges from 15 to 64 years (Statistics South Africa 2016), and this closely lines up to the respondents in this study whose ages range from 20 to 72 years, with a mean of 37.81 and a standard deviation of 9.10 .

\section{Educational qualifications}

A total of 934 (29.4\%) respondents hold a bachelor's degree or higher, $1274(40.1 \%)$ possess a diploma, $789(24.8 \%)$ have matric, and $143(4.5 \%)$ have less than 12 years of schooling, while data was missing data for 40 (1.3\%).

\section{Management and tenure}

Those in management positions totalled 1156 (36.4\%) and those in non-management positions represented 1983 $(62.4 \%)$, while data was missing data for $41(1.3 \%)$. As far as tenure at their present company is concerned, this varied between 1 month and 42 years, with a mean of 8.49 and a standard deviation of 7.45 .

\section{Economic sectors}

The organisations were categorised into three sectors. A total of $1981(62.3 \%)$ respondents fall within the private sector, 480 $(15.1 \%)$ are parastatal and $719(22.6 \%)$ are government departments, for example the Department of Trade and Industry, the Department of Tourism, and so on.

From the above mentioned respondents' demographic characteristics, it is evident that the respondents represent a broad cross-section of the South African workforce.

\section{Descriptive data}

Presented in Table 1 is the total number of observations, means, standard deviations and Cronbach's alphas of all variables contained within this study.

The means and standard deviations presented in Table 1 can serve as baseline information for future studies. However, the different instrument scores varied, with TL showing the lowest mean $($ mean $=2.516$; standard deviation $=0.972$; number of observations $=3139$ ) and CE showing the highest (mean $=65.743 ;$ standard deviation $=9.321$; number of observations $=3180$ ). The reliability information presented in the last column of Table 1 is important and will be discussed below.

\section{Reliability}

Also illustrated in Table 1, the PA instrument registers a high Cronbach's alpha of 0.930 . Reliability was computed for the IIB instrument, which resulted in Cronbach's alphas of 0.951. Reliability for the PP instrument was 0.843 and, for the CE

TABLE 1: Descriptive data $(N=3180)$.

\begin{tabular}{llcccc}
\hline Scale & Item content & Observations & Mean & $\begin{array}{c}\text { Standard } \\
\text { deviation }\end{array}$ & $\alpha$ \\
\hline PA & Performance appraisal & 3180 & 58.133 & 16.072 & 0.930 \\
IIB & Individual innovative behaviour & 3180 & 36.662 & 9.608 & 0.951 \\
PP & Proactive personality & 3180 & 53.792 & 8.971 & 0.843 \\
CE & Corporate entrepreneurship & 3180 & 65.743 & 9.321 & 0.762 \\
TL & Transformational leadership & 3139 & 2.516 & 0.972 & 0.946 \\
WE & Work engagement & 3180 & 37.998 & 10.156 & 0.900 \\
AC & Affective commitment & 3180 & 34.318 & 9.947 & 0.806 \\
\hline
\end{tabular}


instrument the Cronbach's alpha was 0.762. Also, reliability for the TL instrument was 0.946 and, for the WE instrument was 0.900. Lastly, for the AC instrument, the resulting Cronbach's alpha was 0.806. All seven instruments have a Cronbach's alpha above 0.6, which suggests that the reliability of all instruments is acceptable.

\section{Model assessment results}

The output of the mediation and moderation analysis is presented below, per hypothesis.

\section{Model 1}

Baron and Kenny's (1986) four steps for mediation are summarised below (supported by the Sobel test).

Step 1: The effect of the independent variable (PA) on the dependent variable (IIB) is equal to $0.0524(p<0.0001)$, with a $95 \%$ confidence interval of $0.0256-0.0791$. Therefore, PA has a non-zero relationship with IIB since it was statistically significant in the analysis. The results from Step 1 indicate that mediation is possible, and that PA has a significant influence on IIB.

Step 2: The effect of PA on WE is equal to $0.2338(p<0.0001)$, with a $95 \%$ confidence interval of $0.2133-0.2543$. The effect of PA on AC is equal to $0.2599(p<0.0001)$, with a $95 \%$ confidence interval of $0.2401-0.2797$. Therefore, PA has a non-zero relationship with both WE and AC since it was statistically significant in the analysis. The results from Step 2 indicate that mediation is possible.

Step 3: The effect of WE on IIB controlling for PA is equal to $0.2970(p<0.0001)$, with a 95\% confidence interval of $0.2516-0.3425$. The effect of AC on IIB controlling for PA is equal to $0.1322(p<0.0001)$, with a $95 \%$ confidence interval of 0.0872-0.1771. Both WE and AC have a non-zero relationship with IIB since it was statistically significant in the analysis. The results from Step 3 indicate that mediation is possible.

Step 4: The effect of PA on IIB controlling for both WE and AC is equal to $0.0522(p<0.0001)$, with a $95 \%$ confidence interval of $0.0254-0.0789$ and a total mediation effect of 0.1038 (indirect effect).

Effects (WE and AC): The bootstrap estimated indirect effect of both mediators of PA on IIB is equal to 0.1038 , and the direct effect is equal to 0.0522 . The $95 \%$ bias-corrected bootstrap confidence interval (5000 trials) for the indirect effect is $0.0882-0.1208$, and since zero is not in the confidence interval, it can be concluded that the indirect effect is significantly different from zero.

Summary: The direct effect from PA to IIB equals 0.0524 and is statistically significant $(p<0.0001)$. The indirect effect from PA to IIB equals 0.1038 and is statistically significant. There is evidence of mediation of the effect of PA on IIB given that the indirect effect is statistically significant. The results are supported by the WE Sobel $z$ value of 15.6373 $(p<0.0001)$, and the AC Sobel $z$ value of $10.1179(p<0.0001)$. The interaction is equal to $0.0013(p<0.3232)$ which denotes that PP has a weak moderation effect, and it is also not significant.

\section{Model 2}

Baron and Kenny's (1986) four steps for mediation are summarised below (supported by the Sobel test).

Step 1: The effect of PA on IIB is equal to $0.0812(p<0.0001)$, with a $95 \%$ confidence interval of $0.0486-0.1138$. Therefore, PA has a non-zero relationship with IIB since it was statistically significant in the analysis. The results from Step 1 indicate that mediation is possible, and that PA has a significant influence on IIB.

Step 2: The effect of PA on WE is equal to $0.2375(p<0.0001)$, with a $95 \%$ confidence interval of $0.2169-0.2581$. The effect of PA on AC is equal to $0.2628(p<0.0001)$, with a $95 \%$ confidence interval of 0.2429-0.2828. Therefore, PA has a non-zero relationship with both WE and AC since it was statistically significant in the analysis. The results from Step 2 indicate that mediation is possible.

Step 3: The effect of WE on IIB controlling for PA is equal to 0.4487 ( $p<0.0001)$, with a 95\% confidence interval of $0.3999-0.4976$. The effect of AC on IIB controlling for PA is equal to $0.0868(p<0.0006)$, with a $95 \%$ confidence interval of 0.0371-0.1365. Both WE and AC have a non-zero relationship with IIB since it was statistically significant in the analysis. The results from Step 3 indicate that mediation is possible.

Step 4: The effect of PA on IIB controlling for both WE and AC is equal to $0.0697(p<0.0001)$, with a $95 \%$ confidence interval of $0.0381-0.1014$ and a total mediation effect of 0.1294 (indirect effect).

Effects (WE and AC): The bootstrap estimated indirect effect of both mediators of PA on IIB is equal to 0.1294, and the direct effect is equal to 0.0697 . The $95 \%$ bias-corrected bootstrap confidence interval (5000 trials) for the indirect effect is $0.1111-0.1493$, and since zero is not in the confidence interval, it can be concluded that the indirect effect is significantly different from zero.

Summary: The direct effect from PA to IIB equals 0.0812 and is statistically significant $(p<0.0001)$. The indirect effect from PA to IIB equals 0.1294 and is statistically significant. There is evidence of mediation of the effect of PA on IIB given that the indirect effect is statistically significant. The results are supported by the WE Sobel $z$ value of $15.6373(p<0.0001)$, and the AC Sobel $z$ value of $10.1179(p<0.0001)$. The interaction is equal to 0.0816 $(p<0.0001)$ which denotes that TL has a strong moderation effect, and it is also significant. 


\section{Model 3}

Baron and Kenny's (1986) four steps for mediation are summarised below (supported by the Sobel test).

Step 1: The effect of PA on IIB is equal to $0.0596(p<0.0001)$, with a $95 \%$ confidence interval of $0.0301-0.0891$. Therefore, PA has a non-zero relationship with IIB since it was statistically significant in the analysis. The results from Step 1 indicate that mediation is possible, and that PA has a significant influence on IIB.

Step 2: The effect of PA on WE is equal to $0.2338(p<0.0001)$, with a $95 \%$ confidence interval of $0.2133-0.2543$. The effect of PA on AC is equal to $0.2599(p<0.0001)$, with a $95 \%$ confidence interval of $0.2401-0.2797$. Therefore, PA has a non-zero relationship with both WE and AC since it was statistically significant in the analysis. The results from Step 2 indicate that mediation is possible.

Step 3: The effect of WE on IIB controlling for PA is equal to $0.4371(p<0.0001)$, with a 95\% confidence interval of 0.3884-0.4857. The effect of AC on IIB controlling for PA is equal to $0.0715(p<0.0040)$, with a $95 \%$ confidence interval of 0.0228-0.1202. Both WE and AC have a non-zero relationship with IIB since it was statistically significant in the analysis. The results from Step 3 indicate that mediation is possible.

Step 4: The effect of PA on IIB controlling for both WE and AC is equal to $0.0579(p<0.0001)$, with a $95 \%$ confidence interval of 0.0284-0.0874 and a total mediation effect of 0.1208 (indirect effect).

Effects (WE and AC): The bootstrap estimated indirect effect of both mediators of PA on IIB is equal to 0.1208 , and the direct effect is equal to 0.0579 . The $95 \%$ bias-corrected bootstrap confidence interval (5000 trials) for the indirect effect is $0.1026-0.1404$, and since zero is not in the confidence interval, it can be concluded that the indirect effect is significantly different from zero.

Summary: The direct effect from PA to IIB equals 0.0596 and is statistically significant $(p<0.0001)$. The indirect effect from PA to IIB equals 0.1208 and is statistically significant. There is evidence of mediation of the effect of PA on IIB given that the indirect effect is statistically significant. The results are supported by the WE Sobel $z$ value of $15.6373(p<0.0001)$, and the AC Sobel $z$ value of $10.1179(p<0.0001)$. The interaction is equal to $0.0098(p<0.0001)$ which denotes that $\mathrm{CE}$ has a weak moderation effect, and it is also significant.

The overall results of the model assessment are summarised in Table 2.

As revealed in Table 2, some of the hypotheses related to IIB were accepted. The strongest model was Model 2, providing the best evidence of the relationship between the selected variables. It is also evident from the results that PA has the most significant influence on IIB in Model 2. Furthermore,
TABLE 2: Summary of the hypothesised results.

\begin{tabular}{l}
\hline Hypothesis \\
\hline Model 1: The relationship between PA and - Partially rejected. \\
IIB (where PA relates to IIB) is mediated by \\
WE and AC, and moderated by PP \\
Model 2: The relationship between PA and - Fully effect: Mediation; No moderation. \\
IIB (where PA relates to IIB) is mediated by \\
WE and AC, and moderated by TL \\
Model 3: The relationship between PA and - Fully acfect: Mediation; Moderation. \\
IIB (where PA relates to IIB) is mediated by \\
WE and AC, and moderated by CE \\
AC, affective commitment; WE, work engagement; PA, performance appraisal; IIB, individual \\
innovative behaviour; TL, transformational leadership; CE, corporate entrepreneurship; PP,
\end{tabular}
innovative behaviour; $T L$, transformational leadership; $C E$, corporate entrepreneurship; $P P$, proactive personality.

TL and WE are thus the primary concern in an optimal PAinnovation model.

\section{Discussion}

Although many models on the PA-innovation link are available, complex models are limited. Some of these complex models were tested in this study. The South African context may be unique, given the legislative framework within which PA is administered. Evidence of empirical research testing different complex models on the PA-innovation relationship is seemingly lacking, particularly within the South African environment. This study provided clarity on the specific PAinnovation models applicable within the South African context.

The respondents represented the South African workforce well, in as far as gender, race and age were concerned. In addition, the demographic characteristics of the respondents were closely related to the information presented in the Quarterly Labour Force Survey publication (Statistics South Africa 2016). This study used a relatively large sample consisting of 3180 employees from 53 organisations for the analysis.

Seven variables were included in the model, namely PA, IIB, PP, TL, CE, WE and AC. The results reveal that PA directly influences innovation in all three models. Furthermore, PA has the most significant influence on innovation in Model 2. The PA-innovation relationship is mediated by WE and AC, with WE having the greatest effect. Transformational leadership and CE moderate the PA-innovation relationship, with TL having the strongest effect and CE having almost no effect. This is consistent with the research conducted by Oke et al. (2009), Sethibe and Steyn (2016), and Tipu et al. (2012). Several empirical studies provide evidence that there is a strong connection between innovation and climate (Lin \& Liu 2012; Michaelis et al. 2010; Shanker et al. 2012), which is not aligned with the results in this study. Furthermore, PP does not moderate the PA-innovation relationship, which is inconsistent with the results of studies by Seibert et al. (2001), and Tai and Mai (2016). The results showed an enhancing effect: as PA and TL increased, innovation increased. Presented in Figure 2 is a revised model on the PA-innovation link.

In Figure 2, PP is the grey dotted parts of the model, as this stated model did not materialise. Application of the present statistical tools revealed that PA directly influences IIB. 


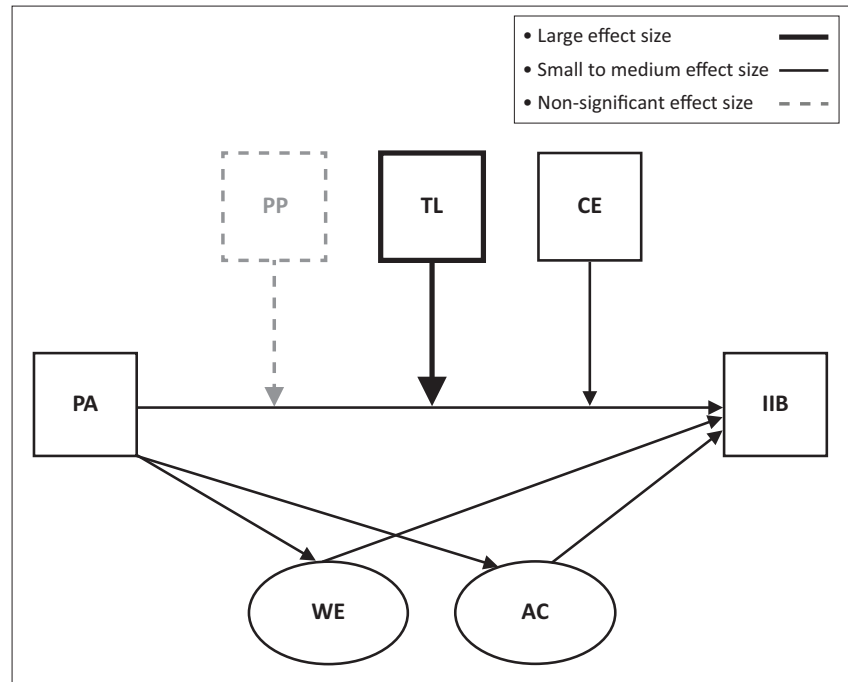

$\mathrm{AC}$, affective commitment; WE, work engagement; PA, performance appraisal; IIB, individual innovative behaviour; $\mathrm{TL}$, transformational leadership; $\mathrm{CE}$, corporate entrepreneurship; $\mathrm{PP}$, proactive personality.

FIGURE 2: Revised performance appraisal-innovation model with mediators and moderators.

The study shows the importance of including WE, AC and especially TL when investigating the PA-innovation relationship. The results indicate the importance of using PA to enhance innovation. In a study by Jafri (2010), AC is positively related to innovation which is partially aligned with the results in this study.

It is evident that TL has a much bigger part to play in enhancing innovation. Managing employees with TL practices and instilling WE may be at the root of innovation in organisations. According to the literature, PP is theorised to be the basis of innovative behaviour (Fuller \& Marler 2009; Seibert et al. 2001), which is not consistent with the results of this study. The revised model makes a significant contribution to understanding the PA-innovation link.

\section{Theoretical implications}

The PA-innovation relationship and the various variables included in the model were justified through the General Systems Theory and the Input-Transformation-Output model. Not all variables were found to contribute equally to innovation, and the nature of the contribution was specified. The research thus contributes to academic literature and theory on the PAinnovation link within the South African context, where no prior studies of this nature, complexity and using this method have been conducted in one report. This study has led to an increase in knowledge and the unveiling of optimal models on the PA-innovation relationship. A valuable contribution to the body of knowledge was made as a best-fit PA-innovation model has been specified. Applying a specific set of mediator and moderator variables to enhance innovation is evident.

\section{Practical implications}

The outcomes of this study are expected to be of value to all stakeholders and may perhaps assist human resources practitioners and managers to appropriately assign resources to particular organisational variables, thereby enhancing innovation within organisations. It is evident that TL has a much larger role to play in enhancing innovation than PP or CE. Recruitment of proactive employees, managing these employees with TL practices and instilling a culture of CE may be at the root of innovation in organisations. However, managers should focus on managing employees with TL practices to effectively drive innovation within the organisation as TL has the largest positive impact on the PAinnovation relationship. This evidence-based information would assist managers to increase innovative behaviour, performance, the competitive advantage, organisational success, growth and organisational survival accordingly.

\section{Limitations}

It is advisable to acknowledge the various restrictions of a study when interpreting the outcomes of that study. This investigation was subject to several particular limitations that merit mentioning. The first limitation is that it makes use of a cross-sectional survey design, focusing on quantitative data. Levin (2006) proposes that cross-sectional studies are carried out at a specific point in time and offer no hint of the sequence of events, thus making it impossible to infer causality from the study. However, to overcome the limitations of a cross-sectional study, a longitudinal or experimental design is proposed.

Only respondents' perceptions were used which posed the second limitation. Had managers or supervisors been included in the reporting, or had organisational statistics, such as registered patents, been used, the results may have been more explanatory. Therefore, multi-source and multimethod research is suggested to future researchers.

Another limitation of the study is that respondents represented the South African labour force as a single unit. Thus, additional research is suggested in this regard as it can be anticipated that there might be differences per organisation and also sector-wide.

The fourth limitation was the sampling. Organisations from the different economic sectors were treated as homogenous. To overcome this limitation, it is suggested that future research be conducted per economic sector as organisations are different and experience varied dynamics and trajectories. The range for generalising the results is limited due to the use of a convenience sample. However, to overcome this limitation, respondents were selected at random from each organisation, each of these organisations varied in size and economic sector (private sector, parastatals, and government departments).

\section{Acknowledgements Competing interests}

The authors declare that they have no financial or personal relationships that may have inappropriately influenced them in writing this article. 


\section{Authors' contributions}

N.G.M. was the main author of the article. R.S. was the supervisor of N.G.M and the co-author of the article.

\section{Funding information}

This research received no specific grant from any funding agency in the public, commercial or not-for-profit sector.

\section{Data availability statement}

Quantitative data was used in this study and this data is available on written request.

\section{Disclaimer}

The views and opinions expressed in this article are those of the authors and do not necessarily reflect the official policy or position of any affiliated agency of the authors.

\section{References}

Abbaspour, P., 2015, 'Effect of strategic orientation and HRM strategies on organisational strategic performance: Examining mediating role of strategic learning and innovation', An International Peer-Reviewed Journal (Trends in Life Sciences) 4(4), 125-132.

Agarwal, U.A., 2014, 'Linking justice, trust and innovative work behaviour to work engagement', Personnel Review 43(1), 41-73. https://doi.org/10.1108/PR-02 2012-0019

Agarwal, U.A., Datta, S., Blake-Beard, S. \& Bhargava, S., 2012, 'Linking LMX, innovative work behaviour and turnover intentions: The mediating role of work engagement',
Career Development International 17(3), 208-230. https://doi.org/10.1108/ 13620431211241063

Aggarwal, A. \& Thakur, G.S.M., 2013, 'Techniques of performance appraisal - A review', International Journal of Engineering and Advanced Technology (IJEAT) 2(3), 617-621.

Ahmed, I., Mohammad, S.K. \& Islam, T., 2013, 'The relationship between perceived fairness in performance appraisal and organisational citizenship behaviour in the banking sector of Pakistan: The mediating role of organisational commitment' International Journal of Management and Innovation 5(2), 75-88.

Aktharsha, U.S. \& Sengottuvel, A., 2016, 'Knowledge sharing behaviour and innovation capability: HRM practices in hospitals', SCMS Journal of Indian Management 13(1), 118-130.

Allen, N.J. \& Meyer, J.P., 1990, 'The measurement and antecedents of affective, continuance and normative commitment to the organisation', Journal of
Occupational Psychology 63(1), 1-18. https://doi.org/10.1111/j.2044-8325.1990. Occupational
tb00506.x

Alsalami, E., Behery, M. \& Abdullah, S., 2014, 'Transformational leadership and its effects on organisational learning and innovation: Evidence from Dubai', Journa of Applied Management and Entrepreneurship 19(4), 61-81. https://doi. org/10.9774/GLEAF.3709.2014.oc.00006

Antonakis, J., Avolio, B.J. \& Sivasubramanian, N., 2003, 'Context and leadership: An examination of the nine-factor full-range leadership theory using the Multifacto Leadership Questionnaire', The Leadership Quarterly 14(2003), 261-295. https:// doi.org/10.1016/S1048-9843(03)00030-4

Avolio, B.J., Bass, B.M. \& Jung, D.I., 1999, 'Re-examining the components of transformational and transactional leadership using the Multifactor Leadership Questionnaire', Journal of Occupational and Organisational Psychology 72(4), 441-462. https://doi.org/10.1348/096317999166789

Ayers, R.S., 2013, 'Building goal alignment in federal agencies' performance appraisal programs', Public Personnel Management 42(4), 495-520. https://doi. org/10.1177/0091026013496077

Bal, Y., Bozkurt, S. \& Ertemsir, E., 2014, 'A study on determining the relationship between strategic HRM practices and creating innovation in organisations', The International Journal of Contemporary Management 13(2), 23-36.

Baron, R.M. \& Kenny, D.A., 1986, 'The moderator-mediator variable distinction in Social Psychological research: Conceptual, strategic, and statistical considerations'
Journal of Personality and Social Psychology 51(6), 1173-1182. https://doi. org/10.1037/0022-3514.51.6.1173

Bass, B.M., 1985, Leadership and performance beyond expectations, 1st edn., The Free Press, New York, NY.

Bateman, T.S. \& Crant, J.M., 1993, 'The proactive component of organisational behaviour: A measure that correlates', Journal of Organisational Behaviour 14(2), 103-118. https://doi.org/10.1002/job.4030140202

Blankenship, C.J., 2002, Effect of performance appraisal training on rehabilitation supervisor's knowledge and discomfort in appraisal of subordinate's performance, Southern Illinois University, Carbondale, IL.
Boswell, W.R. \& Boudreau, J.W., 2000, 'Employee satisfaction with performance appraisals and appraisers: The role of perceived appraisal use', Human Resource Development Quarterly11(3), 283-299. https://doi.org/10.1002/1532-1096(200023)11:3\%3C283:: Quarterly 11(3), 283-299.h
AID-HRDQ6\%3E3.0.CO;2-3

Bryman, A.D., 2012, Social research methods, 4th edn., Oxford University Press, New York, NY

Burns, J.M., 1978, Leadership, 1st edn., Harper \& Row, New York, NY.

Cascio, W.F., 2010, Managing human resources: Productivity, quality of work life, profits, 8th edn., McGraw-Hill Irwin, New York, NY.

Chen, C. \& Huang, J., 2009, 'Strategic human resource practices and innovation performance - The mediating role of knowledge management capacity', Journal of Business Research 62(1), 104-114. https://doi.org/10.1016/j.jbusres.2007.11.016

Choi, B.K., Moon, H.K. \& Ko, W., 2013, 'An organisation's ethical climate, innovation, and performance: Effects of support for innovation and performance evaluation ManagementDecision 51(6), 1250-1275. https://doi.org/10.1108/MD-Sep-2011-0334

Dalota, M. \& Perju, A., 2010, 'Human resource management and the company's innovation', Romanian Economic and Business Review 5(4), 122-131.

DeNisi, A.S. \& Pritchard, R.D., 2006, 'Performance appraisal, performance management and improving individual performance: A motivational framework' Management and Organisation Review 2(2), 253-277. https://doi.org/10.1111/ j.1740-8784.2006.00042.x

Dess, G.G., Ireland, R.D., Zahra, S.A., Floyd, S.W., Janney, J.J. \& Lane, P.J., 2003, 'Emerging issues in corporate entrepreneurship', Journal of Management 29(3), 351-378. https://doi.org/10.1016/S0149-2063(03)00015-1

Fuller, B. \& Marler, L.E., 2009, 'Change driven by nature: A meta-analytic review of the proactive personality literature', Journal of Vocational Behaviour 75(3), 329-345. https://doi.org/10.1016/j.jvb.2009.05.008

Grobler, P.A., Wärnich, S., Carrell, M.R., Elbert, N.F. \& Hatfield, R.D., 2006, Human resource management in South Africa, 3rd edn., Thompson Learning, London.

Grote, R.C., 1996, The complete guide to performance appraisal, 1st edn., AMACOM, New York, NY.

Hair, J.F., Black, W.C., Babin, B.J. \& Anderson, R.E., 2009, Multivariate data analysis, 7 th edn., Pearson Education International, Upper Saddle River, NJ.

Hayes, A.F., 2013, Introduction to mediation, moderation, and conditional process analysis: A regression-based approach, 1st edn., Guilford Press, New York, NY.

Hornsby, J.S., Kuratko, D.F. \& Zahra, S.A., 2002, 'Middle managers' perception of the internal environment for corporate entrepreneurship: Assessing a measurement
scale', Journal of Business Venturing 17(3), 253-273. https://doi.org/10.1016/ scale', Journal of Business

Jafri, M.H., 2010, 'Organisational commitment and employee's innovative behavior: A study in retail sector', Journal of Management Research 10(1), 62-68.

Judge, T.A. \& Ferris, G.R., 1993, 'Social context of performance evaluation decisions', Academy of Management Journal 36(1), 80-105. https://doi.org/10.2307/256513

Kast, F.E. \& Rosenzweig, J.E., 1972, 'General systems theory: Applications for organisation and management', Academy of Management Journal 15(4), 447-465. https://doi.org/10.2307/255141

Khoury, G.C. \& Analoui, F., 2004, 'Innovative management model for performance appraisal: The case of the Palestinian public universities', Management Research appraisal: The case of the Palestinian public universities', Managemer
News 27(1), 56-73. https://doi.org/10.1108/01409170410784356

Kim, T., Hon, A.H.Y. \& Lee, D., 2010, 'Proactive personality and employee creativity: The effects of job creativity requirement and supervisor support for creativity', Creativity Research Journal 22(1), 37-45. https://doi.org/10.1080/10400410903579536

Kleysen, R.F. \& Street, C.T., 2001, 'Toward a multi-dimensional measure of individual innovative behaviour', Journal of Intellectual Capital 2(3), 284-296. https://doi. org/10.1108/EUM0000000005660

Lamba, S. \& Choudhary, N., 2013, 'Impact of HRM practices on organisational commitment of employees', International Journal of Advancements in Research \& Technology 2(4), 407-423.

Levin, K.A., 2006, 'Study design III: Cross-sectional studies', Evidence-Based Dentistry 7(1), 24-25. https://doi.org/10.1038/sj.ebd.6400375

Lin, C.Y.Y \& Liu, F.C., 2012, 'A cross-level analysis of organisational creativity climate and perceived innovation: The mediating effect of work motivation', European Journal of Innovation Management 15(1), 55-76. https://doi.org/10.1108/ 14601061211192834

Ling, T.C. \& Nasurdin, A.M., 2011, 'Human resource management practices and organisational innovation: Assessing the mediating role of knowledge management effectiveness', Electronic Journal of Knowledge Management 9(2), 155-167.

Matookchund, N.G., 2019, 'Performance appraisal as driver of individual innovation within and across organisations', Doctoral thesis, School of Business Leadership, University of South Africa.

McFadzean, E., O'Loughlin, A. \& Shaw, E., 2005, 'Corporate entrepreneurship and innovation: Part 1: The missing link', European Journal of Innovation Management 8(3), 350-372. https://doi.org/10.1108/14601060510610207

Mei, P.L., Ong, S.F. \& Pei, M.T., 2017, 'Positioning ethics and social responsibility as a strategic tool in employees' affective commitment - Evidence from Malaysian small-medium-sized enterprises (SMEs), Annals in Social Responsibility 3(1), 2-22. https://doi.org/10.1108/ASR-12-2016-0013

Meyer, J.P. \& Allen, N.J., 1997, Commitment in the workplace: Theory, research, and application, 1st edn., Sage, CA

Michaelis, B., Stegmaier, R. \& Sonntag, K., 2010, 'Shedding light on followers' innovation implementation behaviour: The role of transformational leadership, commitment to change, and climate for initiative', Journal of Managerial Psychology 25(4), 408-429. https://doi.org/10.1108/02683941011035304 
Mitchell, L.D., 2010, 'Emotional responses to performance appraisal feedback: Implications for organisations', The Journal of Applied Business and Economics 11(4), 82-108.

Montshiwa, V.T. \& Moroke, N.D., 2014, 'Assessment of the reliability and validity of student-lecturer evaluation questionnaire: A case of North West University', Mediterranean Journal of Social Sciences 5(14), 352-364. https://doi.org/10.5901/ mjss.2014.v5n14p352

Morris, M.H., Kuratko, D.F. \& Covin, J.G., 2010, Corporate entrepreneurship \& innovation - Entrepreneurial development within organisations 3rd edn., Cengage Learning, $\mathrm{OH}$.

Muller, M., Bezuidenhout, M. \& Jooste, K., 2011, Healthcare service management 2nd edn., Juta, Cape Town.

Nickols, F., 2007, 'Performance appraisal: Weighed and found wanting in the balance', The Journal of Quality and Participation 30(1), 13-16, 47.

Oke, A., Munshi, N. \& Walumbwa, F.O., 2009, 'The influence of leadership on innovation process and activities', Organisational Dynamics 38(1), 64-72. https:// doi.org/10.1016/j.orgdyn.2008.10.005

Phan, P.H., Wright, M., Ucbasaran, D. \& Tan, W.L., 2009, 'Corporate entrepreneurship: Current research and future directions', Journal of Business Venturing 24(3), 197-205. https://doi.org/10.1016/j.jbusvent.2009.01.007

Preacher, K.J. \& Hayes, A.F., 2004, 'SPSS and SAS procedures for estimating indirect effects in simple mediation models', Behaviour Research Methods, Instruments, \& Computers 36(4), 717-731. https://doi.org/10.3758/BF03206553

Punch, K.F., 2005, Introduction to social research: Quantitative and qualitative approaches, 2nd edn., Sage, London.

Runfeng, Y., 2011, 'Influence of goal orientation in performance appraisal on staff innovative behaviour: Mediating effect of innovative climate', Proceedings of the $8^{\text {th }}$ International Conference on Innovation and Management, Kitakyushu, Japan, pp. 445-451.

Schaufeli, W.B. \& Bakker, A.B., 2004, Utrecht Work Engagement Scale: Preliminary manual, Unpublished manuscript, Utrecht University, Utrecht, Netherlands.

Schaufeli, W.B., Bakker, A.B. \& Salanova, M., 2006, 'The measurement of work engagement with a short questionnaire: A cross-national study', Educational and Psychological Measurement 66(4), 701-716. https://doi.org/10.1177/0013164405282471

Schaufeli, W.B., Salanova, M., González-Romá, V. \& Bakker, A.B., 2002, 'The measurement of engagement and burnout: A two sample confirmatory factor analytic approach', Journal of Happiness Studies 3(1), 71-92. https://doi. org/10.1023/A:1015630930326

Seibert, S.E., Kraimer, M.L. \& Crant, J.M., 2001, 'What do proactive people do? A longitudinal model linking proactive personality and career success', Personnel Psychology 54(4), 845-874. https://doi.org/10.1111/j.1744-6570.2001.tb00234.x

Sethibe, T. \& Steyn, R., 2015, 'The relationship between leadership styles, innovation and organisational performance: A systematic review', South African Journal of Economic and Management Sciences 18(3), 325-337. https://doi.org/10.17159/ 2222-3436/2015/v18n3a3

Sethibe, T. \& Steyn, R., 2016, Towards a comprehensive model on the relationship between leadership styles, organisational climate, innovation and organisational performance, University of South Africa, Midrand.
Shanker, R., Bhanugopan, R. \& Fish, A., 2012, 'Changing organisational climate for innovation through leadership: An exploratory review and research agenda', Review of Management Innovation \& Creativity 5(14), 105-118.

Shipton, H., West, M.A., Dawson, J., Birdi, K. \& Patterson, M., 2006, 'HRM as a predictor of innovation', Human Resource Management Journal 16(1), 3-27. https://doi.org/10.1111/j.1748-8583.2006.00002.x

Siaguru, F., 2011, 'Performance appraisal systems: Procedural and implementation issues in Papua New Guinea', Journal of Management Policy and Practice 12(5), 116-127.

Statistics South Africa, 2016, Quarterly labour force survey - Quarter 4: 2016, Statistical release P0211, Statistics South Africa website, viewed 05 March, 2017, from http://www.statssa.gov.za/publications/P0211/P02114thQuarter2016.pdf.

Steyn, R., 2010, 'The development and validation of the quality of performance appraisal systems questionnaire', Paper presented at the $27^{\text {th }}$ International Congress of Applied Psychology, Melbourne, Australia, p. 947.Steyn, R. 2012, 'Human resource practices and employee attitudes: A study of individuals in ten South African companies', Alternation 5(2012), 167-184.

Steyn, R., Bezuidenhout, M.L. \& Grobler, A., 2017, 'Human resource practices and affective organisational commitment: A sectoral comparative study', SA Journal of Human Resource Management 15(1), 1-9. https://doi.org/10.4102/sajhrm. v15i0.841

Strydom, A.S., 2013, The influence of organisational behaviour variables on corporate entrepreneurship, University of South Africa, Midrand.

Subramaniam, M. \& Youndt, M.A., 2005, 'The influence of intellectual capital on the types of innovative capabilities', Academy of Management Journal 48(3), 450-463. https://doi.org/10.5465/amj.2005.17407911

Swanepoel, B.J., Erasmus, B.J. \& Schenk, H.W., 2008, South African human resource management: Theory \& practice, 4th edn., Juta \& Co Ltd., Cape Town.

Tai, H.T. \& Mai, N.Q., 2016, 'Proactive personality, organisational context, employee creativity and innovative capability: Evidence from MNCs and domestic corporations', International Journal of Organisational Analysis 24(3), 370-389. corporations', International Journal of Organis

Teece, D.J., 2018, 'Dynamic capabilities as (workable) management systems theory', Journal of Management \& Organisation 24(3), 359-368. https://doi.org/10.1017/ jmo. 2017.75

Tipu, S., Ryan, J. \& Fantazy, K., 2012, 'Transformational leadership in Pakistan: An examination of the relationship of transformational leadership to organisational culture and innovation propensity', Journal of Management \& Organisation 18(4), 461-480. https://doi.org/10.5172/jmo.2012.997

Wolins, R.G., 2012, Everyday optimum leadership: Practicing servant leadership Other centred focused, 1st edn., West Bow Press, Bloomington, IN.

Wright, P.M. \& Kehoe, R.R., 2007, Human resource practices and organisational commitment: A deeper examination, pp. 1-22, Centre of Advanced Human Resource Studies, New York, NY.

Wu, H., Sears, L.E., Coberley, C.R. \& Pope, J.E., 2016, 'Overall well-being and supervisor ratings of employee performance, accountability, customer service, innovation, presocial behaviour, and self-development', Journal of Occupational and Environmenta Medicine 58(1), 35-40. https://doi.org/10.1097/JOM.0000000000000612 